\title{
Growth inhibition and chemo-radiosensitization of esophageal squamous cell carcinoma by survivin-shRNA lentivirus transfection
}

\author{
CHANGLIN ZHOU ${ }^{1 *}$, LIN ZHANG ${ }^{1 *}$ and PENG XU ${ }^{2}$ \\ ${ }^{1}$ Department of Oncology, Jining First People's Hospital, Jining, Shandong 272011; \\ ${ }^{2}$ Department of Thoracic Surgery, Ji'nan Central Hospital Affiliated to \\ Shandong University, Ji'nan, Shandong 250013, P.R. China
}

Received September 6, 2016; Accepted February 22, 2018

DOI: $10.3892 / \mathrm{ol} .2018 .9280$

\begin{abstract}
Esophageal cancer is one of the most common types of cancer worldwide, and it has a poor prognosis. Chemo-radiotherapy resistance and cancer relapse are among the most difficult issues in its treatment. Identifying the underlying molecular mechanisms is critical for developing novel therapies. Survivin has been previously suggested to be overexpressed in esophageal cancer cells. The present study identified that down-regulation of survivin sensitized esophageal cancer cells to chemo-radiotherapy. Consistent with previous studies, the present study indicated that survivin was overexpressed in 4 esophageal squamous carcinoma cell lines. Short hairpin RNA delivered by lentivirus successfully knocked down survivin in these cancer cell lines. Consequently, down-regulation of survivin impaired their colony-forming, migratory and invasive capabilities, while the overexpression of survivin in normal human esophagus epithelial cells improved their resistance to cisplatin, paclitaxel and radiation. Survivin knockdown induced apoptosis in esophageal cancer KYSE-150 and ECA-109 cell lines when exposed to the aforementioned chemo-radiotherapy treatments. These results indicate that survivin expression sustains growth in esophageal cancer cells, and confers resistance to chemo-radiotherapy. Targeted survivin ablation may be a promising strategy against esophageal tumor relapse and chemo-radioresistance.
\end{abstract}

Correspondence to: $\mathrm{Dr}$ Peng Xu, Department of Thoracic Surgery, Ji'nan Central Hospital Affiliated to Shandong University, 105 Jiefang Road, Ji'nan, Shandong 250013, P.R. China

E-mail: xupengsci@163.com

*Contributed equally

Key words: esophageal cancer, chemo-radiosensitization, survivin, short hairpin RNA, lentivirus

\section{Introduction}

Esophageal cancer (EsC) is one of the least studied and deadliest cancers worldwide because of its extremely aggressive nature and poor survival rate (1). Due to its aggressive nature, it ranks sixth in all cancer-associated mortalities in China and other developing countries in 2014 (2). While many other types of cancer are expected to decrease in incidence over the next 10 years by 2025, the prevalence of esophageal cancer is expected to increase by $140 \%$ (2). There are two primary histological types of esophageal cancer. Adenocarcinoma is prevalent in the United States of America and certain other developed countries, while squamous cell carcinoma is the most common esophageal cancer worldwide, including Japan, China and other developing counties $(1,3)$. Treatment primarily includes surgery, chemotherapy and radiotherapy, depending on the stages of the disease. Despite intensive investigation, patient prognosis has not significantly improved over the past 20 years, with a 5 -year survival rate of $<20 \%(1,4)$. Combined preoperative chemotherapy and radiotherapy (chemo-radiotherapy) has demonstrated certain benefits (5-8). However, a significant proportion of patients respond poorly to chemotherapy and/or radiotherapy (9), which have severe side effects. Furthermore, tumor resistance and relapse occur despite chemo-radiotherapy $(10,11)$. Understanding the molecular mechanisms conveying tumor resistance is important.

Survivin is a member of the inhibitor of apoptosis protein (IAP) family (12). Members of IAPs bind directly with caspase 3,7 and 9, resulting in function inhibition and/or ubiquitination, and consequent degradation of these caspase proteins $(13,14)$. Survivin was revealed to be overexpressed in multiple types of cancer, but was absent or expressed at low levels in normal terminally-differentiated tissues (15). High levels of survivin expression have been detected in cisplatin-resistant thyroid cancer cell lines, flutamide-resistant prostate cancer cells and radiation-resistant pancreatic cancer cells (16).

Survivin is also expressed in esophageal carcinomas (17), and a high expression level was associated with poor prognosis in esophageal cancer patients $(18,19)$. Targeted down-regulation of survivin by RNA interference (RNAi) repressed the growth of KYSE510 cells, an esophageal squamous carcinoma (ESC) 
cell line (20). Survivin may bind to the Inhibitor of nuclear factor $\beta$ promoter, and enhance nuclear factor- $\mathrm{kB}$ expression, maintaining the oncogenic characteristics of esophageal cancer cells (21). Despite these data, the role of survivin in the mechanisms of chemo-radioresistance in different types of esophageal cancer has been poorly defined. The present study demonstrated that lentivirus-mediated knockdown of survivin in ESC cell lines suppressed the tumorigenic capacity of these cells, and enhanced the sensitivity to conventional chemotherapy and radiotherapy in vitro.

\section{Materials and methods}

Cell lines and cell culture. Human esophagus epithelial cells (HEEC) were purchased from the American Type Culture Collection (Manassas, VA, USA) and cultured in Dulbecco's modified Eagle's medium (DMEM) (Lonza Group, Ltd., Basel, Switzerland). KYSE-150, TE-1 and ECA-109 and TE-13 were obtained from the Cell Bank of Type Culture Collection of Chinese Academy of Sciences (Shanghai, China). The 4 ESC cell lines were cultured in RPMI-1640 (Gibco; Thermo Fisher Scientific, Inc., Waltham, MA, USA) with $10 \%$ fetal bovine serum (FBS; Gibco; Thermo Fisher Scientific, Inc.). All cells were incubated at $37^{\circ} \mathrm{C}$ with $5 \% \mathrm{CO}_{2}$. The native survivin expression in these four ESC cell lines and HEEC was evaluated using western blotting. KYSE-150, ECA-109 and TE-1 were selected to evacuate the efficiency of survivin short hairpin RNA (shRNA) transfection. KYSE-150 and ECA-109 were further used in colony formation, cell invasion, wound healing assays and their sensitivity to chemotherapeutic drugs or radiotherapy was assessed.

Plasmids and viruses. Forward oligo (5'-CCGGCTGGACAG AGAAAGAGCCAAGCTCGAGCTTGGCTCTTTCTCTGT CCAGTTTTTG-3') and reverse oligo (5'-AATTCAAAAACT GGACAGAGAAAGAGCCAAGCTCGAGCTTGGCTCTTT CTCTGTCCAG-3') DNA were annealed and ligated to EcoR I and Age I digested pLKO.1 vector (22) (a gift from Bob Weinberg, Addgene plasmid \#8453). The resulting recombinant pLKO.1 (or empty pLKO.1 as control) was co-transfected with pMD2.G and psPAX2 (supplied as a gift from Didier Trono, Addgene plasmid \#12259 and \#12260) into 293T cells (ATCC Inc., Manassas, VA, USA). Lentivirus particles in culture supernatant were collected 24 and $48 \mathrm{~h}$ after transfection and filtered through a 0.45 um membrane, which were used immediately or aliquoted and frozen at $-80^{\circ} \mathrm{C}$ until use. For virus transfection, half of the culture medium $2 \mathrm{ml}$ DMEM+10\% FBS + Penicillin (100 U/ml)-Streptomycin (100 $\mu \mathrm{g} / \mathrm{ml}$ ) (all Gibco; Thermo Fisher Scientific) was immediately changed to $1,000 \mu 1$ Lentivirus and $(1,000 \mu \mathrm{l}$ DMEM+10\% FBS+ Penicillin-Streptomycin $+2 \mu 1$ Polybrene) in the 6-well plate. Prior to continuing culture in the incubator $\left(37^{\circ} \mathrm{C}, 5 \% \mathrm{CO}_{2}\right)$ for $4-5 \mathrm{~h}$, the medium was changed to fresh DMEM+10\% FBS + Penicillin (100 U/ml)-Streptomycin $(100 \mu \mathrm{g} / \mathrm{ml})$ and cultured overnight. Transfection was performed using Entranster-R4000 regent (Engreen Biosystem New Zealand, Ltd., Auckland, New Zealand) according to the manufacturer's protocol. Briefly, cells were plated in 24-well plates in $500 \mu \mathrm{l}$ DMEM and 10\% FBS without antibiotics and allowed to grow to $90 \%$ confluency. Both plasmid DNA $(2.5 \mu \mathrm{g})$ and Entranster-R4000 reagent were diluted in $50 \mu \mathrm{l}$ of serum-free Opti-MEM (Invitrogen; Thermo Fisher Scientific, Inc.) medium separately and incubated for $5 \mathrm{~min}$. Following incubation, plasmid DNA and Entranster-R4000 reagent were mixed gently and added to each well containing cells and medium. $6 \mathrm{~h}$ later, medium was changed to (DMEM+10\% FBS + PS).Cells were incubated at $37^{\circ} \mathrm{C}$ for $24 \mathrm{~h}$ in an incubator containing $5 \% \mathrm{CO}_{2}$ at full humidity. The plate was subjected to centrifugation (Eppendorf, Hamburg, Germany) at 1,200 x g for $30 \mathrm{~min}$ at room temperature. For quantitative polymerase chain reaction (qPCR) analysis of survivin expression, another round of infection was performed at day 5 after the first infection.

The full length of the coding region of human survivin (accession number:NM_001168.2) was cloned to the pcDNA3.1 plasmid (Invitrogen, Thermo Fisher Scientific, Inc.). A total of $4 \mu \mathrm{g}$ recombinant plasmid was transfected into the cultured cell lines with $6 \mu$ l Lipofectamine ${ }^{\circledR} 2000$ (Invitrogen; Thermo Fisher Scientific, Inc.) for each well of 6-well plates. A blank vector was used as the negative control.

Reverse transcription- $q P C R(R T-q P C R)$. Cells subjected to survivin shRNA lentivirus or control virus treatment for $24 \mathrm{~h}$ were lysed with TRIzol ${ }^{\circledR}$ reagent (Ambion; Thermo Fisher Scientific, Inc.) and frozen at $-80^{\circ} \mathrm{C}$. RNA was extracted according to the protocol of the manufacturer. cDNA was synthesized using random six primers according to the protocol of the reverse transcription kit (cat. no. 240589; Tiangen Biotech, Beijing, China). qPCR was performed using a SYBR green-based protocol (Takara Bio, Inc., Otsu, Japan; cat. no. RR820L) (23). Primers were designed and synthesized by Sangon Biotech. (Shanghai, China). Relative gene expression was determined using the $2^{-\Delta \Delta \mathrm{Cq}}$ method (23).

Western blot. Cultured cells were lysed with radioimmunoprecipitation buffer (Solarbio, Beijing, China; cat. no. R0030). Protein concentration was determined with a bicinchoninic acid assay according to kit protocols provided by the manufacturer (cat. no. 23250; Pierce; Thermo Fisher Scientific, Inc.). A total of $50 \mu \mathrm{g}$ total protein from each sample was separated using SDS-PAGE (10\% gel), transferred to a polyvinylidene fluoride membrane, blocked by $5 \%$ non-fat milk at room temperature for $1 \mathrm{~h}$. The membranes were then incubated with survivin $(1: 3,000), \beta$-actin $(1: 5,000)$ or cleaved Poly (adenosine 5 '-diphosphate-ribose) polymerase (PARP1; 1:1,000) antibodies (cat. nos. ab76424, ab227387 and ab32561, respectively; all from Abcam, Cambridge, UK) overnight at $4^{\circ} \mathrm{C}$. Subsequent to washing 3 times with TBST and incubated with peroxidase conjugated anti-rabbit secondary antibody $(1: 10,000$; cat. no. SAB3700928; Sigma-Aldrich; Thermo Fisher Scientific, Inc.) at room temperature for $1 \mathrm{~h}$, the bands were detected with a chemiluminescence kit (cat. no. WBKLS0100; EMD Millipore, Billerica, MA, USA) and exposed to X-ray film (Kodak, Rochester, NY, USA).

Colony formation, cell invasion and wound healing assays. A total of $\sim 1,000$ cells in the logarithmic growth period were seeded in 6-well dishes. Giemsa staining (5\% solution, $30 \mathrm{~min}$ at room temperature) was performed when colonies became visible under a light microscope with x100 magnification. A colony was defined as consisting of at least 50 cells. For 
A

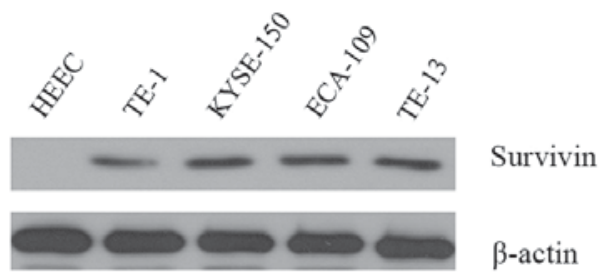

B

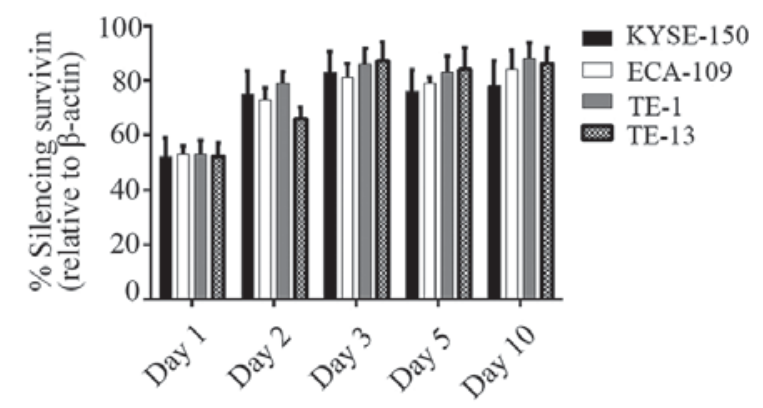

C

KYSE-150 ECA-109 TE-1

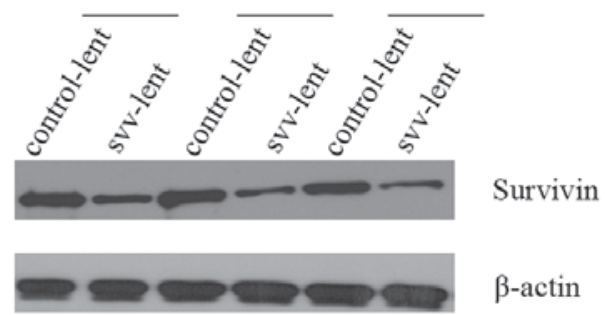

Figure 1. Survivin expression in esophageal cell lines and RNAi knockdown of survivin. (A) Western blot analysis of survivin expression in the normal esophageal HEEC cell line and 4 esophageal squamous carcinoma cell lines. (B) Survivin expression was detected by reverse transcription quantitative polymerase chain reaction at different days following lentivirus delivery of RNAi, svv-lent or control lentivirus vector, cont-lent. (C) Western blot analysis at day 2. RNAi, RNA interference; svv-lent, supernatant virus; control-lent, empty lentiviral vector.

the invasion assay, a transwell insert with $8 \mu \mathrm{m}$ pore size (Corning Incorporated, Corning, NY, USA) was coated with Matrigel $^{\circledR}$. ESC cells resuspended in serum-free RPMI-1640 medium were added to the Transwell insert, and then placed into 24-well dishes containing RPMI-1640 medium with $10 \%$ FBS. Cells were further cultured for $24 \mathrm{~h}$ at $37^{\circ} \mathrm{C}$ with $5 \%$ $\mathrm{CO}_{2}$. The invading cells adhering to the underside of the insert were stained with $0.05 \%$ crystal violet at room temperature for $20 \mathrm{~min}$ and counted under a light microscope with x200 magnification. Wound healing assay was performed according to a previously published protocol (24) with minor adjustment. Briefly, adherent ESC cells in $35 \mathrm{~mm}$ dishes were scratched with $10 \mu \mathrm{l}$ pipette tips, washed twice with PBS, and cultured $\left(37^{\circ} \mathrm{C}, 5 \% \mathrm{CO}_{2}\right)$ in serum-free medium at $37^{\circ} \mathrm{C}$ overnight. The width of the scratch was then calculated. A terminal deoxynucleotidyl transferase dUTP nick end labeling (TUNEL) assay was performed according to the protocol of the manufacturer (Promega Corporation, Madison, WI, USA).

Chemotherapeutic drugs and radiotherapy. Cells were treated with various concentrations of cisplatin $(0.5-64 \mu \mathrm{g} / \mathrm{ml})$ or paclitaxel $(0.25-32 \mu \mathrm{g} / \mathrm{ml})$ for $24 \mathrm{~h}$ or radiation for 3 or 6 Gy. MTT assays were then performed, as described previously (21), to evaluate the live cells. For the TUNEL assay, cells were treated with $1 \mu \mathrm{g} / \mathrm{ml}$ paclitaxel, $2 \mu \mathrm{g} / \mathrm{ml}$ cisplatin or 3 Gy radiation.

Statistical analysis. All results presented were obtained from three independent experiments, with triplicate wells for the RT-qPCR, MTT and TUNEL assays. The data are presented as the mean \pm SEM. One-way analysis of variance (ANOVA) was used to compare between groups. The post-hoc test used following the ANOVA to perform the pairwise comparisons was the Least Significant Difference test. Analysis was performed with SPSS software (version 13.0; SPSS Inc., Chicago, IL, USA) $\mathrm{P}<0.05$ was considered to indicate a statistically significant difference.

\section{Results}

Survivin is overexpressed in ESC cell lines and knocked down by short hairpin (sh)RNA. A panel of ESC cell lines was tested for survivin expression. Western blot analysis indicated that survivin was not expressed in the normal esophageal HEEC cell line, whilst highly expressed in the 4 ESC cell lines, TE-1, TE-13, KYSE-150 and ECA-109. No marked difference in survivin expression was observed among these cancer cell lines (Fig. 1A). To clarify if survivin expression in these cancer cell lines was knocked down by shRNA, oligonucleotides were cloned, which had been previously verified for their efficiency in survivin knockdown (25), into lentiviral vectors, transfected it into $293 \mathrm{~T}$ cells and the supernatant virus (svv-lent) was harvested. The supernatant virus was used to transduce these 4 cell lines for 1, 2, 3, 5 or 10 days. RT-qPCR was performed to assess survivin expression. (Fig. 1B) indicates that survivin was knocked down efficiently in all 4 cell lines, with $~ 50 \%$ at day 1 and up to $80 \%$ at day 3 . Western blot analysis performed at day 2 following transduction also demonstrated that svv-lent efficiently inhibited survivin expression (Fig. 1C) compared with the empty control lentiviral vector (control-lent).

Survivin knockdown impairs the colony-forming, migratory and invasive capabilities of ESC cells. A clonogenic assay was performed in ECA-109 and KYSE-150 cell lines to evaluate the role of survivin in tumorigenicity. Svv-lent infection for 24 h significantly reduced colony formation of the 2 cell lines, while cont-lent transduction had no effect, compared with no infection. A long exposure time to the RNAi virus additionally reduced the number of colonies (Fig. 2A and B). A Matrigel ${ }^{\circledR}$ invasion assay was also performed in KYSE-150 and ECA-109 cells. Svv-lent infection inhibited the invasive ability of these 2 cell lines. The number of invading cells was reduced up to $50 \%$ in KYSE-150 cells and $\sim 75 \%$ in ECA-109 cells

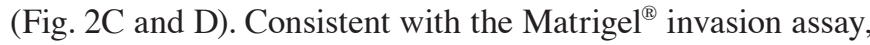
the wound healing assay additionally confirmed that survivin knockdown affected ESC cell migration (Fig. 2E and F).

Survivin overexpression facilitates chemo-radiotherapy resistance. The cytotoxic effects of cisplatin and paclitaxel, 2 commonly used drugs for chemotherapy in esophageal cancer, were initially measured in ESC and HEEC cells. Cells seeded 
A

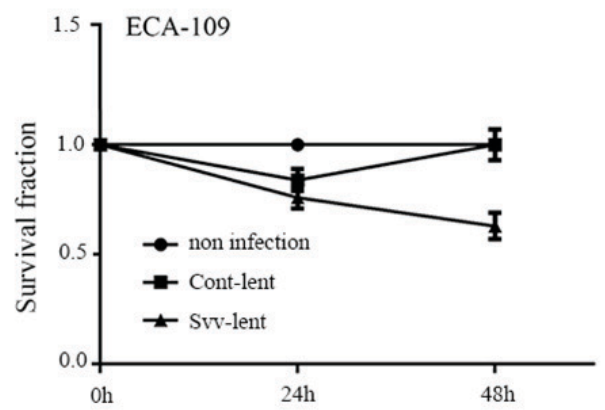

$\mathrm{C}$

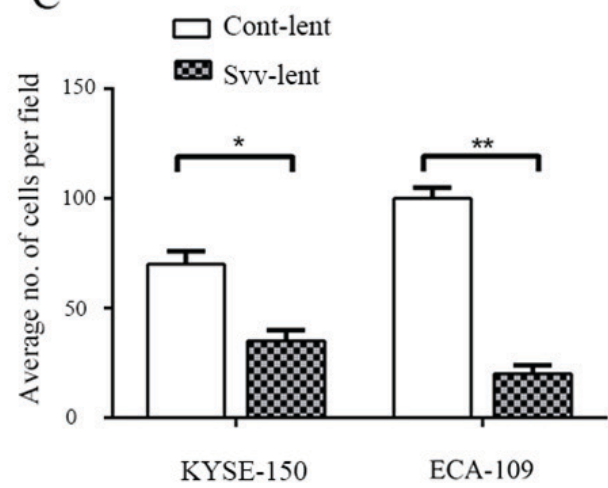

$\mathrm{E}$

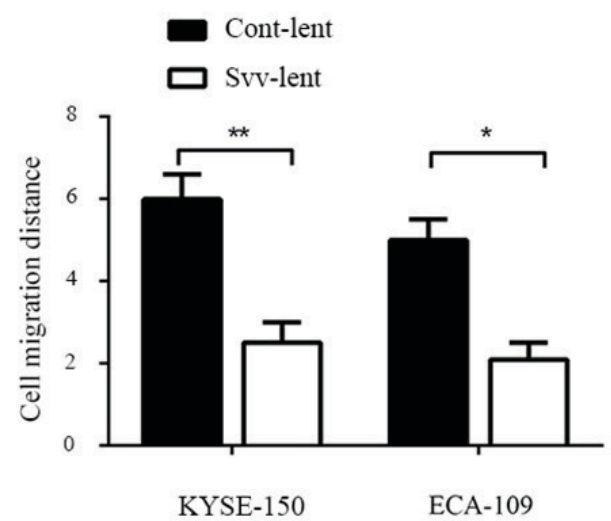

$\mathrm{B}$

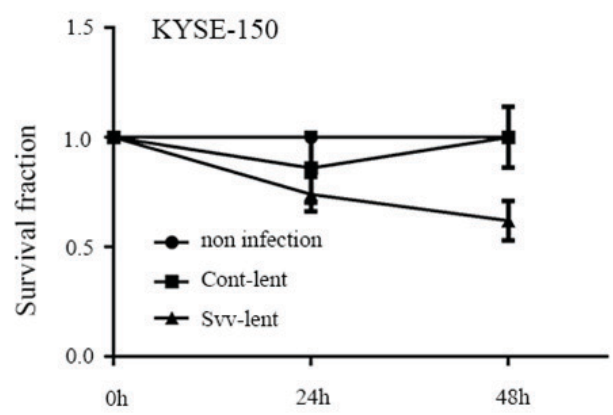

$\mathrm{D}$

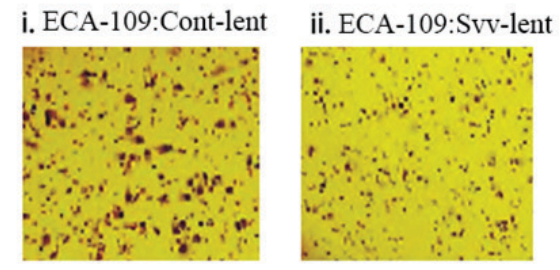

$\mathrm{F}$

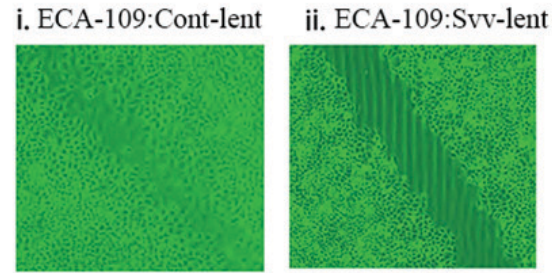

Figure 2. Survivin knockdown inhibits tumorigenic ability of ESC cells in vitro. Colony formation assay of (A) ECA-109 and (B) KYSE-150 cells infected with survivin shRNA lentivirus or control lentivirus. Cell invasion assay of KYSE-150 and ECA-109 cells infected with survivin or control shRNA lentivirus. (C) The average number of migrated cells in each light microscope field (magnification, x200). (D) Representative images of migrated cells stained with crystal violet in each group in light microscope (magnification, $\mathrm{x} 40$ ). Wound healing assay of KYSE-150 and ECA-109 cells infected with survivin or control shRNA lentivirus. (E) The average migrated distance of cells in each group. (F) Representative image to show the distance of migration in the two groups. Results are representative image of at least 3 repeats. ${ }^{*} \mathrm{P}<0.05$ and ${ }^{* *} \mathrm{P}<0.01$.

in 96-well plates were treated with various concentrations of the drugs for $24 \mathrm{~h}$; the resulting live cells were measured by an MTT assay. HEEC cells were fairly sensitive to cisplatin and paclitaxel, with half maximal inhibitory concentrations $\left(\mathrm{IC}_{50}\right)$ of 2.6 (cisplatin) and 1.3 (paclitaxel) $\mu \mathrm{g} / \mathrm{ml}$. All of the 4 ESC cell lines, however, were resistant to the 2 drugs. The $\mathrm{IC}_{50}$ of cisplatin in the TE1, ECA109, KYSE-150 and TE-13 cell lines were $18,47.5,54.5$ and $13.7 \mu \mathrm{g} / \mathrm{ml}$, respectively. The $\mathrm{IC}_{50}$ of paclitaxel in these 4 cell lines were $4.7,3.9,13.5$ and $3.6 \mu \mathrm{g} / \mathrm{ml}$, respectively (Fig. 3A and B).

Similarly, HEEC cells and the 4 ESC cell lines were assessed for their sensitivity to radiotherapy. The majority of the cells ( $3 \mathrm{~Gy}, \leq 50 \%$; $6 \mathrm{~Gy}, \leq 75 \%$ ) were killed by radiation (Fig. 3C). However, HEEC cells were more sensitive to radiation compared with ESC cells; for example, 3 Gy irradiation killed $\sim 75 \%$ HEEC cells, while $\sim 50 \%$ KYSE-150, ECA109 and TE-1 cells survived (Fig. 3C). To identify if the resistance exhibited by these cancer cell lines was due to survivin expression, a survivin-pcDNA3.1 plasmid was transfected into normal HEEC cells, and the empty pcDNA3.1 plasmid was used as a control. A cytotoxicity test was repeated. Survivin overexpression enhanced HEEC resistance to cisplatin and paclitaxel, while the control vector (HEEC-neo) had no effect (Fig. 3D). 
A

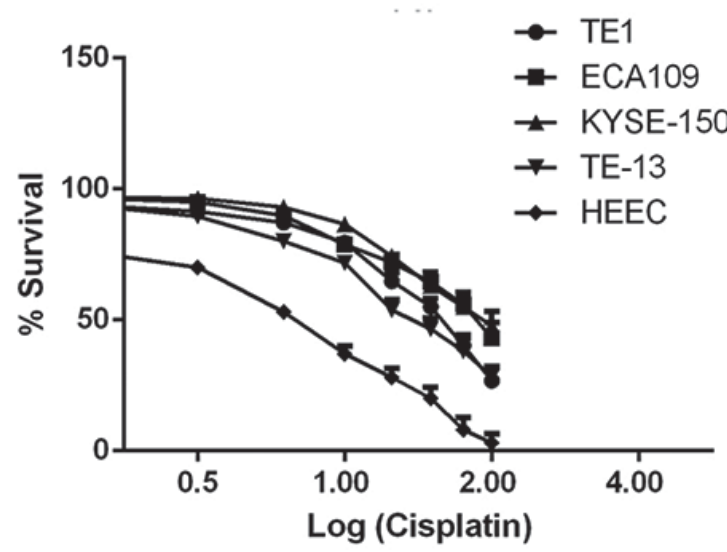

$\mathrm{C}$

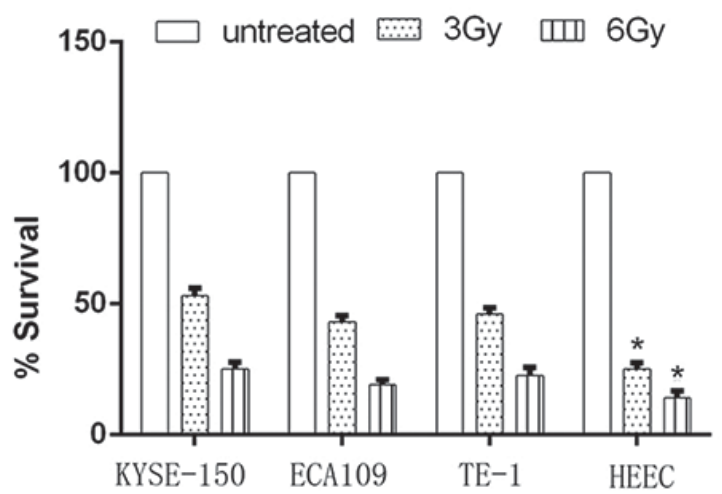

B

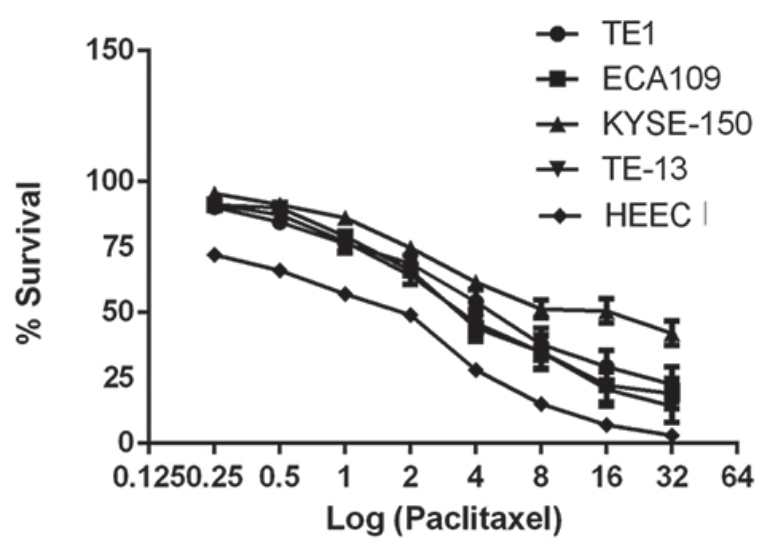

$\mathrm{D}$
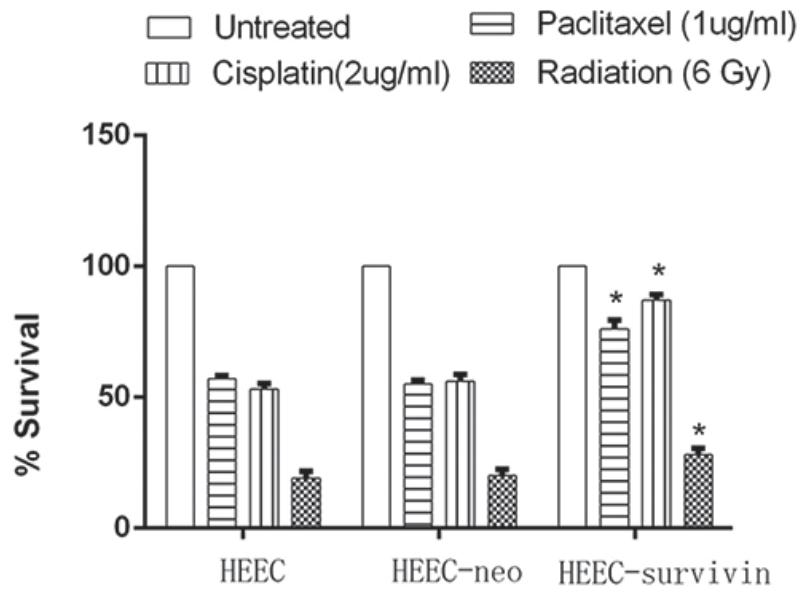

Figure 3. Overexpression of survivin in normal HEEC cells facilitates chemo-radioresistance. ESC and HEEC cells were treated with various concentration of (A) cisplatin or (B) paclitaxel for $24 \mathrm{~h}$ or (C) the indicated dose radiation, and cell viability was measured by MTT experiment. "P $<0.05$ vs. KYSE-150, ECA-109 or TE-1 cells. (D) Survivin was overexpressed in HEEC cells and cell sensitivity to chemo-radiotherapy was measured. "P $<0.05$ vs. HEEC cells or HEEC cells infected with empty lentivirus (HEEC-neo). All experiments were repeated at least 3 times and data presented as mean \pm standard error of the mean. ESC, esophageal squamous carcinoma; HEEC, Human esophagus epithelial cells; neo, empty plasmid vector.

HEEC with survivin overexpression also exhibited elevated resistance to radiation (Fig. 3D), indicating the role of survivin in chemo- and radiotherapy resistance of esophageal cells.

Survivin knockdown promotes ESC cells apoptosis and chemo-radiotherapy sensitivity. KYSE-150 and ECA-109 cells infected with svv-lent or cont-lent, or the non-infected negative controls, were treated with low-dose paclitaxel or cisplatin. TUNEL assays were performed to assess apoptosis in these cells. Compared to negative controls or cont-lent virus infection, drug treatment or svv-lent transfection significantly increased the proportion of apoptotic cells, indicating the role of survivin in ESC cell survival. Cells pretreated with svv-lent to knock down survivin, then exposed to paclitaxel (Fig. 4A and B) or cisplatin (Fig. 4C and D), exhibited an additionally increased ratio of apoptotic cells of $~ 50 \%$, compared to drug treatment alone. Western blot analysis of cleaved PARP1, which was cleaved by caspase 3 or other caspases into an $89 \mathrm{kD}$ fragment during apoptosis, confirmed the results obtained by the TUNEL assay (Fig. 4A and C). Drug treatment and svv-lent transfection induced cell apoptosis, while the combination of transfection with treatment additionally increased the proportion of apoptotic cells. Similarly, survivin knockdown sensitized the KYSE-150 and ECA-109 cells to radiation. Svv-lent transfection followed by irradiation increased the proportion of apoptotic cells (Fig. 4E and F).

\section{Discussion}

Esophageal cancer is one of the most common types of cancer; it is characterized by poor prognosis, high mortality and relapse rate (2). Worldwide, the predominant histological type is squamous cell carcinoma (1). Incidence of esophageal cancer is considered to increase by $0.5 \%$ each year (1). The 1-year survival rate is $<45 \%$, and the 5 -year overall survival is $16.9 \%$ (1). No specific solution to this situation is available at present (2). Survivin is specifically expressed in cancer cells, and is not expressed in normal differentiated tissues, with the exception of a small number of cells including $\mathrm{T}$ cells and hematopoietic progenitor cells (16). This expression pattern makes survivin a promising target of cancer therapy. Shepherdin, which targets heat shock protein 90, the partner and stabilizer of survivin, inhibited breast and prostate cancer cells proliferation in vitro and decreased the growth of tumor xenografts (26). YM155, which inhibits survivin transcription, was demonstrated to 
A

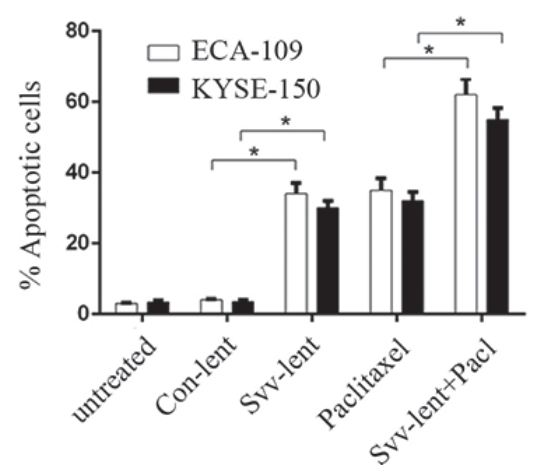

C

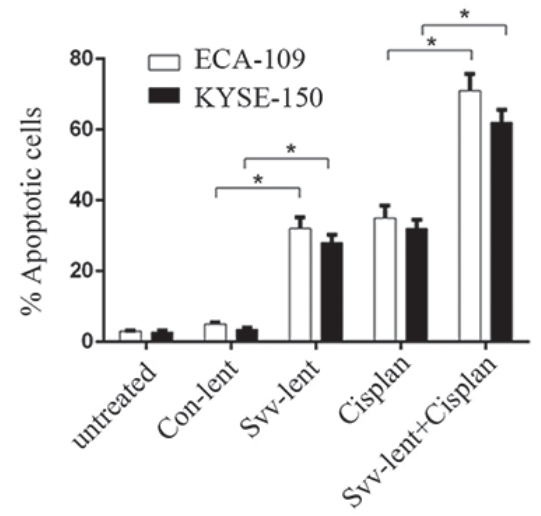

$E$

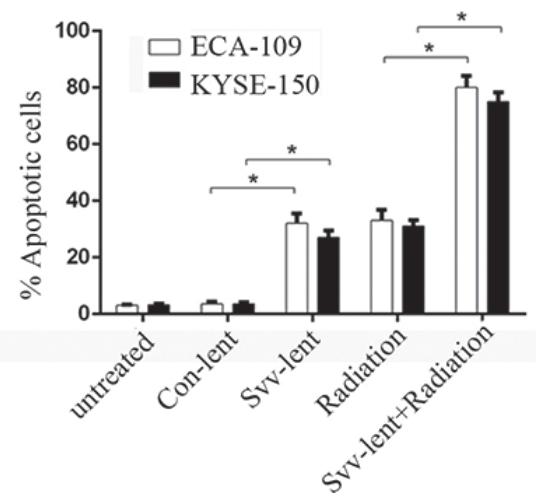

B

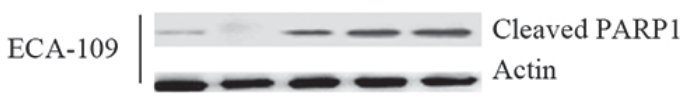

KYSE-150| -

D

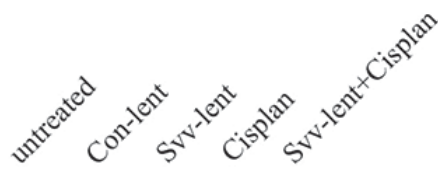

ECA-109

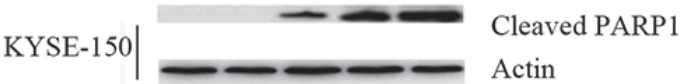

$\mathrm{F}$

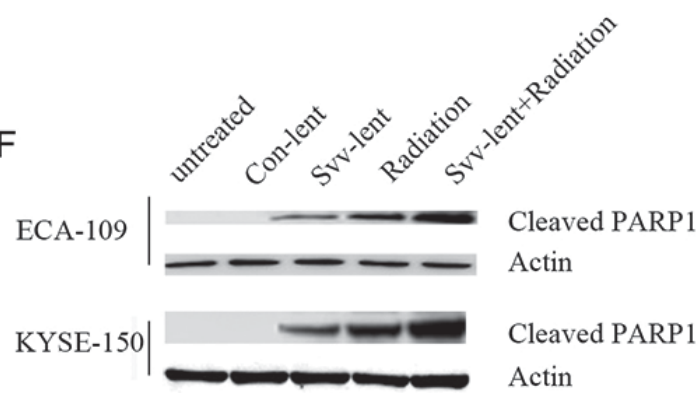

Figure 4. Survivin knockdown promotes ESC cells apoptosis and chemo-radiotherapy sensitivity. KYSE150 and ECA-109 cells were pretreated with survivin shRNA lentivirus or negative control, and then a TUNEL assay was performed to evaluate the apoptosis rate of these cells exposure to paclitaxel, cisplatin and radiation. (A) TUNEL assays were performed to assess apoptotic cells infected with svv-lent, cont-lent or untreated, and then svv-lent- and cont-lent-infected cells treated with $1 \mu \mathrm{g} / \mathrm{ml}$ paclitaxel. (B) Western blotting was performed to detect cleaved PARP1 levels following paclitaxel exposure. (C) TUNEL assays were performed to assess apoptotic cells infected with svv-lent, cont-lent or untreated, and then svv-lent- and cont-lent-infected cells treated with $2 \mu \mathrm{g} / \mathrm{ml}$ cisplatin. (D) Western blotting was performed to detect cleaved PARP1 levels following Cisplan exposure. (E) TUNEL assays were performed to assess apoptotic cells infected with svv-lent, cont-lent or untreated, and then svv-lent- and cont-lent-infected cells treated with 3 Gy radiation. (F) Western blotting was performed to detect cleaved PARP1 levels following radiation exposure. All experiments were performed in triplicate and data presented as mean \pm standard error of the mean. " $\mathrm{P}<0.05$ with comparisons shown by lines. svv-lent, survivin shRNA lentivirus infected; cont-lent, infected with empty lentivirus; Cisplan, cisplatin; svv-lent+pacl, cells pretreated with survivin shRNA exposed to paclitaxel; PARP1, Poly (adenosine 5'-diphosphate-ribose) polymerase 1; shRNA, short hairpin RNA; TUNEL, terminal deoxynucleotidyl transferase dUTP nick end labeling.

be effective in diminishing non-small cell lung cancer cells tumors in xenograft models and other cancer cells $(27,28)$, and now is in phase II clinical studies (www. clinicaltrials. gov; no. NCT01100931) (29,30). In the present study, the role of survivin in chemo-radiotherapy resistance of esophageal cancer cells was evaluated.

The present study identified that survivin is overexpressed in 4 ESC cell lines, but not normal esophageal HEEC cells (Fig. 1A). This is consistent with previous studies that revealed that survivin is overexpressed in squamous cell esophageal cancer, but not adenocarcinoma or Barrett's esophagus (15), and in KYSE-150 cells (20), 1 of the 4 cell lines investigated in the present study. Using lentivirus-mediated RNAi, survivin was successfully knocked down (Fig. 1B and C). Survivin knockdown significantly inhibited ESC cells colony formation, migration and invasion (Fig. 2). Similar effects have been identified in other tumors, for example, breast cancer cells $(31,32)$ and prostate and cervical cancer $(33,34)$. Survivin overexpression in the normal HEEC cell line induced chemo-radioresistance (Fig. 3A-D). As determined 
by MTT experiments, transient transfection of a survivin expression plasmid resulted in more viable cells compared with the control plasmid in HEEC cells treated with paclitaxel, cisplatin or radiation (Fig. 3D). Forced expression of survivin conveying chemo-radioresistance has also been described previously, and overexpression of survivin in HeLa cells resulted in resistance to paclitaxel (16), and resistance to temsirolimus in the renal cancer $786-\mathrm{O}$ cell line (35). Overexpression of Multidrug resistance gene and survivin in RPMI8226/VCR multiple myeloma cells conferred multidrug resistance (36).

The results of the present study also indicated that survivin knockdown in ESC cell lines increased their sensitivity to chemo-radiotherapy (Fig. 4A-F). When ESC cells were exposed to paclitaxel, cisplatin or radiation, survivin knockdown increased the proportion of apoptotic cells, as measured by a TUNEL assay and verified by an elevated cleaved PARP1 level. A similar role of survivin in other types of cancer has been identified in vitro and in animal models previously (37-40). Knockdown of survivin in head and neck squamous cell carcinoma enhanced sensitivity to chemotherapy and radiation (25), and overexpression of an alternative splicing form of survivin in breast cancer cells preserved cell viability to doxorubicin, while YM155 treatment attenuated it (41).

To conclude, the results of the present study suggested that survivin serves a key role in ESC carcinogenesis, proliferation, migration and invasion. Forced expression of survivin confers resistance to chemo-radiotherapy in normal esophageal cells. Down-regulation of survivin suppressed tumor growth and migration, and increased tumor sensitivity to conventional therapies.

\section{Acknowledgements}

Not applicable.

\section{Funding}

No funding was received.

\section{Availability of data and materials}

The datasets used and/or analyzed during the current study are available from the corresponding author on reasonable request.

\section{Authors' contributions}

PX conceived of the study. CZ and LZ performed the experiments. PX analyzed the data and all authors contributed to the final manuscript.

\section{Ethics approval and consent to participate}

The present study was approved by the Ethics Committee of Ji'nan Central Hospital Affiliated to Shandong University.

\section{Patient consent for publication}

Not applicable.

\section{Competing interests}

The authors declare that they have no competing interests.

\section{References}

1. Zhang Y: Epidemiology of esophageal cancer. World J Gastroenterol 19: 5598-5606, 2013.

2. Napier KJ, Scheerer M and Misra S: Esophageal cancer: A Review of epidemiology, pathogenesis, staging workup and treatment modalities. World J Gastrointest Oncol 6: 112-120, 2014.

3. Lin Y, Totsuka Y, He Y, Kikuchi S, Qiao Y, Ueda J, Wei W, Inoue $\mathrm{M}$ and Tanaka $\mathrm{H}$ : Epidemiology of esophageal cancer in Japan and China. J Epidemiol 23: 233-242, 2013.

4. Hiripi E, Jansen L, Gondos A, Hiripi E, Jansen L, Gondos A, Emrich K, Holleczek B, Katalinic A, Luttmann S, et al: Survival of stomach and esophagus cancer patients in Germany in the early 21st century. Acta Oncol 51: 906-914, 2012.

5. van Hagen P, Hulshof MC, van Lanschot JJ, Steyerberg EW, van Berge Henegouwen MI, Wijnhoven BP, Richel DJ, Nieuwenhuijzen GA, Hospers GA, Bonenkamp JJ, et al: Preoperative chemoradiotherapy for esophageal or junctional cancer. N Engl J Med 366: 2074-2084, 2012.

6. Gebski V, Burmeister B, Smithers BM, Foo K, Zalcberg J and Simes J: Survival benefits from neoadjuvant chemoradiotherapy or chemotherapy in oesophageal carcinoma: A meta-analysis. Lancet Oncol 8: 226-234, 2007.

7. Ando N, Kato H, Igaki H, Shinoda M, Ozawa S, Shimizu H, Nakamura T, Yabusaki H, Aoyama N, Kurita A, et al: A randomized trial comparing postoperative adjuvant chemotherapy with cisplatin and 5-fluorouracil versus preoperative chemotherapy for localized advanced squamous cell carcinoma of the thoracic esophagus (JCOG9907). Ann Surg Oncol 19: 68-74, 2012.

8. Sgourakis G, Gockel I, Karaliotas C, Moehler M, Schimanski CC, Schmidberger H and Junginger T: Survival after chemotherapy and/or radiotherapy versus self-expanding metal stent insertion in the setting of inoperable esophageal cancer: A case-control study. BMC Cancer 12: 70, 2012.

9. Liao Z, Cox JD and Komaki R: Radiochemotherapy of esophageal cancer. J Thorac Oncol 2: 553-568, 2007.

10. Smit JK, Faber H, Niemantsverdriet M, Baanstra M, Bussink J, Hollema H, van Os RP, Plukker JT and Coppes RP: Prediction of response to radiotherapy in the treatment of esophageal cancer using stem cell markers. Radiother Oncol 107: 434-441, 2013.

11. Hummel R, Sie C, Watson DI, Wang T, Ansar A, Michael MZ, Van der Hoek M, Haier J and Hussey DJ: MicroRNA signatures in chemotherapy resistant esophageal cancer cell lines. World J Gastroenterol 20: 14904-14912, 2014.

12. Ferrario A, Rucker N, Wong S, Luna M and Gomer CJ: Survivin, a member of the inhibitor of apoptosis family, is induced by photodynamic therapy and is a target for improving treatment response. Cancer Res 67: 4989-4995, 2007.

13. Eckelman BP, Salvesen GS and Scott FL: Human inhibitor of apoptosis proteins: Why XIAP is the black sheep of the family. EMBO Rep 7: 988-994, 2006.

14. Suzuki Y, Nakabayashi Y and Takahashi R: Ubiquitin-protein ligase activity of X-linked inhibitor of apoptosis protein promotes proteasomal degradation of caspase-3 and enhances its anti-apoptotic effect in Fas-induced cell death. Proc Natl Acad Sci USA 98: 8662-8667, 2001.

15. Rodel F, Sprenger T, Kaina B, Liersch T, Rödel C, Fulda S and Hehlgans S: Survivin as a prognostic/predictive marker and molecular target in cancer therapy. Curr Med Chem 19: 3679-3688, 2012.

16. Mobahat M, Narendran A and Riabowol K: Survivin as a preferential target for cancer therapy. Int J Mol Sci 15: 2494-2516, 2014

17. Kato J, Kuwabara Y, Mitani M, Shinoda N, Sato A, Toyama T, Mitsui A, Nishiwaki T, Moriyama S, Kudo J and Fujii Y: Expression of survivin in esophageal cancer: Correlation with the prognosis and response to chemotherapy. Int J Cancer 95: 92-95, 2001.

18. Xia H, Chen S, Huang $\mathrm{H}$ and Ma H: Survivin over-expression is correlated with a poor prognosis in esophageal cancer patients. Clin Chim Acta 446: 82-85, 2015.

19. Rosato A, Pivetta M, Parenti A, Iaderosa GA, Zoso A, Milan G, Mandruzzato S, Del Bianco P, Ruol A, Zaninotto G and Zanovello P: Survivin in esophageal cancer: An accurate prognostic marker for squamous cell carcinoma but not adenocarcinoma. Int J Cancer 119: 1717-1722, 2006. 
20. Wang Y, Zhu H, Quan L, Zhou C, Bai J, Zhang G, Zhan Q and Xu N: Downregulation of survivin by RNAi inhibits the growth of esophageal carcinoma cells. Cancer Biol Ther 4: 974-978, 2005.

21. Zeng W, Li H, Chen Y, Lv H, Liu L, Ran J, Sun X, Bieerkehazhi S, Liu Y, Li X, et al: Survivin activates NF- $\kappa$ B p65 via the IKK $\beta$ promoter in esophageal squamous cell carcinoma. Mol Med Rep 13: 1869-1880, 2016.

22. Moffat J, Grueneberg DA, Yang X, Kim SY, Kloepfer AM, Hinkle G, Piqani B, Eisenhaure TM, Luo B, Grenier JK, et al A lentiviral RNAi library for human and mouse genes applied to an arrayed viral high-content screen. Cell 124: 1283-1298, 2006.

23. Livak KJ and Schmittgen TD: Analysis of relative gene expression data using real-time quantitative PCR and the 2(-Delta Delta C(T)) method. Methods 25: 402-408, 2001

24. Liang CC, Park AY and Guan JL: In vitro scratch assay: A convenient and inexpensive method for analysis of cell migration in vitro. Nat Protoc 2: 329-333, 2007.

25. Khan Z, Khan AA, Prasad GB, Khan N, Tiwari RP and Bisen PS Growth inhibition and chemo-radiosensitization of head and neck squamous cell carcinoma (HNSCC) by survivin-siRNA lentivirus. Radiother Oncol 118: 359-368, 2016.

26. Plescia J, Salz W, Xia F, Pennati M, Zaffaroni N, Daidone MG, Meli M, Dohi T, Fortugno P, Nefedova Y, et al: Rational design of shepherdin, a novel anticancer agent. Cancer Cell 7: 457-468, 2005.

27. Minoda M, Kawamoto T, Ueha T, Kamata E, Morishita M, Harada R, Toda M, Onishi Y, Hara H, Kurosaka M and Akisue T: Antitumor effect of YM155, a novel small-molecule survivin suppressant, via mitochondrial apoptosis in human MFH/UPS. Int J Oncol 47: 891-899, 2015.

28. Nakahara T, Kita A, Yamanaka K, Mori M, Amino N, Takeuchi M, Tominaga F, Hatakeyama S, Kinoyama I, Matsuhisa A, et al: YM155, a novel small-molecule survivin suppressant, induces regression of established human hormone-refractory prostate tumor xenografts. Cancer Res 67: 8014-8021, 2007.

29. Kelly RJ, Thomas A, Rajan A, Chun G, Lopez-Chavez A, Szabo E, Spencer S, Carter CA, Guha U, Khozin S, et al: A phase I/II study of sepantronium bromide (YM155, survivin suppressor) with paclitaxel and carboplatin in patients with advanced non-small-cell lung cancer. Ann Oncol 24: 2601-2606, 2013.

30. Clemens MR, Gladkov OA, Gartner E, Vladimirov V, Crown J, Steinberg J, Jie F and Keating A: Phase II, multicenter, open-label, randomized study of YM155 plus docetaxel as first-line treatment in patients with HER2-negative metastatic breast cancer. Breast Cancer Res Treat 149: 171-179, 2015.

31. Ma WH, Liu YC, Xue ML, Zheng Z and Ge YL: Downregulation of survivin expression exerts antitumoral effects on mouse breast cancer cells in vitro and in vivo. Oncol Lett 11: 159-167, 2016.
32. Wang $\mathrm{H}$ and Ye YF: Effect of survivin siRNA on biological behaviour of breast cancer MCF7 cells. Asian Pac J Trop Med 8: 225-228, 2015

33. Kogo R, How C, Chaudary N, Bruce J, Shi W, Hill RP, Zahedi P, Yip KW and Liu FF: The microRNA-218 Survivin axis regulates migration, invasion, and lymph node metastasis in cervical cancer. Oncotarget 6: 1090-1100, 2015.

34. Wang J, Li Z, Lin Z, Zhao B, Wang Y, Peng R, Wang M, Lu C, Shi G and Shen Y: 17-DMCHAG, a new geldanamycin derivative, inhibits prostate cancer cells through Hsp90 inhibition and survivin downregulation. Cancer Lett 362: 83-96, 2015.

35. Carew JS, Espitia CM, Zhao W, Mita MM, Mita AC and Nawrocki ST: Targeting survivin inhibits renal cell carcinoma progression and enhances the activity of temsirolimus. Mol Cancer Ther 14: 1404-1413, 2015.

36. Tsubaki M, Takeda T, Ogawa N, Sakamoto K, Shimaoka H, Fujita A, Itoh T, Imano M, Ishizaka T, Satou T and Nishida S: Overexpression of survivin via activation of ERK1/2, Akt, and $\mathrm{NF}-\kappa \mathrm{B}$ plays a central role in vincristine resistance in multiple myeloma cells. Leuk Res 39: 445-452, 2015.

37. Shen X, Zheng JY, Shi H, Zhang Z and Wang WZ: Survivin knockdown enhances gastric cancer cell sensitivity to radiation and chemotherapy in vitro and in nude mice. Am J Med Sci 344: 52-58, 2012.

38. Morrison DJ, Hogan LE, Condos G, Bhatla T, Germino N, Moskowitz NP, Lee L, Bhojwani D, Horton TM, Belitskaya-Levy I, et al: Endogenous knockdown of survivin improves chemotherapeutic response in ALL models. Leukemia 26: 271-279, 2012.

39. Kunze D, Erdmann K, Froehner M, Wirth MP and Fuessel S: Enhanced inhibition of bladder cancer cell growth by simultaneous knockdown of antiapoptotic Bcl-xL and survivin in combination with chemotherapy. Int J Mol Sci 14: 12297-12312, 2013.

40. Cui M, Au JL, Wientjes MG, O'Donnell MA, Loughlin KR and $\mathrm{Lu} \mathrm{Z:} \mathrm{Intravenous} \mathrm{siRNA} \mathrm{silencing} \mathrm{of} \mathrm{survivin} \mathrm{enhances} \mathrm{activity}$ of mitomycin C in human bladder RT4 xenografts. J Urol 194: 230-237, 2015.

41. Faversani A, Vaira V, Moro GP, Tosi D, Lopergolo A, Schultz DC, Rivadeneira D, Altieri DC and Bosari S: Survivin family proteins as novel molecular determinants of doxorubicin resistance in organotypic human breast tumors. Breast Cancer Res 16: R55, 2014.

This work is licensed under a Creative Commons Attribution-NonCommercial-NoDerivatives 4.0 International (CC BY-NC-ND 4.0) License. 